\title{
Simulation workshops with first year midwifery students
}

\section{Background}

There is limited knowledge on the future of the midwifery workforce in Australia. Future projections instead focus on nurse shortages (Health Workforce Australia, 2012), and other studies concentrate on the reasons for attrition in midwifery (Pugh et al. 2012) and report the characteristics of Australian midwives (Bogossian et al. 2011). There are difficulties in collecting accurate midwifery workforce data, although, like nurses, they are ageing. The average age of midwives in 2014 was 48 years (Australian Institute of Health and Welfare 2015) which indicates that many will retire within the next two decades.

Many midwives choose not to remain in their jobs, and decisions to leave the workforce can occur soon after completing their degrees (Sullivan, Lock, \& Homer, 2011). Reasons for this are multifactorial, but include an inability to provide ideal standards of care, a lack of managerial support and recognition of their work, and discrepancies between aspirations and actual workplace activities (Ball, Curtis, \& Kirkham, 2002). It is known that Bachelor of Midwifery (BMid) students in the first year of their program often feel a degree of culture shock when introduced to the clinical environment of a maternity unit (Cummins et al. 2014) which can lead to high attrition rates in the first year at university. One way to address this is to prepare the students as much as possible prior to entering clinical settings through experiential learning activities using simulation.

The use of simulation as a method of teaching and learning is gaining momentum and popularity within midwifery education. Simulation is defined as the creation of an event, situation, or environment that closely mirrors what one would encounter in the 'real world' (Cioffi, 2001). Key aspects of learning through simulation are the ability to repeat practice to consolidate learning of technical and non-technical skills and develop competence (Issenberg \& Scalese, 2008). Midwifery is a practice-based discipline and the BMid degree requires that the students undertake clinical practice. To prepare students for clinical practice a number of teaching strategies are implemented, including simulation. 
Skills acquisition in midwifery has changed from the serendipitous traditional 'apprenticeship' way of learning to an approach that encompasses highly authentic learning experiences using simulation (Cant \& Cooper, 2010; Cooper et al., 2012). Safe woman-centred care and development of essential team skills (communication; leadership) are enabled through simulated learning experiences. These assist students to develop a schema of practice in order to assist with socialisation into the workplace.

Simulation is recognised as an engaging technique which leads to effective learning. Various forms of simulation may be used, such as role play, case studies, computer simulations, or mid to high-fidelity mannequins (Arthur, Kable, \& Levett-Jones, 2011; Kelly, Hager, \& Gallagher, 2014; Levett-Jones \& Lapkin, 2014). Human simulation in particular aims to imitate reality whilst offering a skills-based clinical experience in a dedicated environment (Durham \& Alden, 2012).

The benefits of simulation as a strategy for teaching and learning are well documented. Benefits include the ability to combine key technical and non-technical skills in a learner-centred and student active way (Kneebone et al. 2007; Melnyk, 2008); provide a stimulus for reflecting on clinical practice (Nielsen, Stragnell, \& Jester, 2007); and, provide a means of presenting clinical situations infrequently seen in practice (McCaughey \& Traynor, 2010; Weaver, 2011). Students who participated in simulations utilising case studies and role-play have reported increased self-efficacy following these learning opportunities (Kameg et al. 2010; Tawalbeh \& Tubaishat, 2014; Thomas \& Mackey, 2012). Simulation has positively improved knowledge retention (Broussard, 2008), reinforced technical skills including patient assessment (Hayden, 2010), and improved clinical performance (Meyer et al. 2011). Students find it enjoyable, satisfying and can recall experiences during subsequent clinical practice (Guhde, 2011; Rochester et al., 2012).

Simlulation based learning has been enhanced in Australia since the establishment of the Health Workforce Australia (HWA) in 2009. This body, through the Simulated Learning Environments National Project, has subsequently released a report on midwifery simulation education (HWA, 2010). Successive studies from the HWA report have found that simulation was widely used, with up to $17 \%$ clinical program hours allocated (Bogossian et al, 2012), teaching a wide-ranging number of skills with varied pedagogical approaches (Cooper et al., 2012). An earlier study by Cioffi et al., (2005) 
explained how midwifery students reached decisions more quickly and had higher confidence levels in labour and neonatal care after simulation based learning activities. However, it has been acknowledged that simulation techniques cannot replace clinical practise and holistic, womancentred, relationship-based care which is central to midwifery (McKenna et al., 2011).

Empirical studies have demonstrated learning is strengthened in simulation-based education through debriefing (Mahmood \& Darzi, 2004; Savoldelli et al., 2006; Shinnick et al., 2011). The use of deliberate feedback during and after simulation is highly recommended (Cant \& Cooper, 2010; Warland, 2011) and should be structured, constructive and reflective (Cantrell, 2008). Debriefing and feedback discussions allow examination and self-reflection, are critical to student learning, and may be the most important part of the overall simulation experience (Dreifuerst, 2012; McGaghie et al., 2010; Savoldelli et al., 2006; Shinnick et al., 2011).

This project introduced a simulation workshop for first year midwifery students. The purpose of this study was to determine whether pre-clinical simulation workshops enhanced student knowledge, skills and satisfaction with their first midwifery clinical placement. The study's overarching aims were to help students feel capable in their own practice and decision making, and assist with the socialisation within the clinical workplace. Ethical approval was granted for this study by the XX Research Ethics Committee (HREC 2014000120).

\section{Methods}

The simulation (SIM) project consisted of a facilitated two-day simulation workshop for the first year Bachelor of Midwifery students at a large urban university in Sydney. A quasi- experimental pre-test post-test design was conducted (Burns \& Grove, 2005; Minichiello et al., 2004) where the students were asked to complete an online survey before the simulation project, immediately afterwards and then three weeks later after they had completed their clinical placement. Pre and post-test survey design has been commonly used to evaluate clinician's knowledge levels following an intervention program. For example, the assessment of improved knowledge from fetal welfare, obstetric emergency and neonatal resuscitation training program (FONT) (Cooke et al., 2010). 
The students in this study were in the first year of a 3-year Bachelor of Midwifery degree and were undertaking their first clinical subject and related clinical placement. The objectives for the subject, named "Midwifery Practice 1: preparation for practice", included conducting physical and mental health assessments of a childbearing woman and her newborn baby. The subject contained both theoretical lectures and simulated practice, including Observed Structured Clinical Examinations (OSCE) in the midwifery laboratories on campus. Within the subject, which incorporated a number of simulation experiences each week, the students were expected to relate the findings of assessments to the normal ranges and report any deviations. The simulation project described in this paper was built into this subject.

\section{$\underline{\text { The intervention }}$}

Five simulations were undertaken, by ten groups of 7 students. These were based on antenatal, birth, postnatal and neonatal care scenarios. All students took part in playing the parts of the midwife, mother, partner, or the student midwife, with predefined roles, actions and skills to convey. The groups of students rotated around each room with simulations set up to represent the hospital setting complete with props. For example, in the labour and birth room the equipment included a bean bag, mat, birth pool, chair, couch, bed, pinnards stethoscope, a Doppler and a birth pack with a task trainer (Sophie's mum by Model-med International) that simulates normal birth. For the neonatal simulation, an actress was employed to portray a new mother so that students could interact with and assist her to provide basic newborn care. Each simulation and debrief took one hour, and were facilitated by clinical midwifery educators and lecturers. In the 3 weeks prior to the simulation workshop, students had practised all the clinical skills required for each scenario apart from the facilitation of normal labour and birth; students had only viewed a video of this skill before the simulation workshop.

Prior to the simulation, facilitators provided a ten-minute briefing together with a copy of the written scenario for each student in the group. The activities were confidential to those within the room hence they could make errors without any consequences. The briefing consisted of reassuring the students they were in a safe environment, an introduction to the equipment and outline of the case. The students decided amongst themselves the role they would adopt for the scenario and each wore a lanyard depicting their role (Disler et al., 2013). The students completed the scenario in 15-20 minutes 
and then de-gowned or removed props to come out of their role for a debriefing period of 40 minutes (Box 1). During the debriefing the students had the opportunity to discuss their experiences with the respective role/s. The actress playing the mother of the neonate also gave feedback to the group.

The facilitators of the groups all had clinical experience in debriefing, but had not attended formal training. Two were undergoing online simulation training (Health Workforce Australia, 2014 [NHETSim]). All were given instructions on the format of the simulations and debriefing. Simulations used in this project had been created specifically for this purpose and had not been used prior to the workshops. The specified debriefing questions (Box 1) had been previously used in other clinical simulations within the university. The researcher responsible for data collection was one of the team of midwifery lecturers within the Faculty, but did not directly teach the study cohort.

- How did it feel being in your role?

- What was good about the assessment?

- How was the level of information sharing? Was it adequate/appropriate?

- How were the clinical skills (eg. BP assessment and abdomen palpation) performed?

- Was communication adequate?

- What was your key learning from this experience?

- $\quad K e y$ question: "Tell me in $\mathbf{3 0}$ seconds or less what you learned from this simulation?"

All students agreed to take part in the project and gave written consent to do so. Participants were asked to complete an online survey (via the SurveyMonkey ${ }^{\circledR}$ platform) prior to and following the simulation interventions. Participants were then asked to complete the third (last) survey after they had finished their 6-day clinical practice placement to determine how the workshops helped prepare them for their first placement. The third survey was similar to the previous two, but had two extra questions on how the students rated their engagement in the simulation experience, and how they rated it in relation to preparation for practice.

The questions relating to knowledge and skills for the pre and post-tests were developed by the lead author and a simulation specialist and were based on previous questionnaires used in other university simulation initiatives. For example, questions/requests such as 'rate your ability in palpating a 
pregnant woman's abdomen, locating the fetal position and heart sounds' 'rate your understanding of the third stage of labour' and 'how confident are you in performing a postnatal assessment on a woman?' were posed (see Table 1). Four point likert scales were used. Students were asked to rate their understanding and skills at 'very limited', 'somewhat limited', 'reasonable understanding' or 'full understanding'. Questions about confidence or ability had similar descriptors. Each question had an optional 'comments' section for students to elaborate on their responses. Demographic data were also collected on the participants.

\section{$\underline{\text { Data analysis }}$}

Content analysis was used to describe the qualitative data. Content analysis was chosen because it was a systematic and objective means of describing and quantifying phenomena. Process involved subjective interpretation of text content through methodical processes of coding and identifying themes. That is, data were broken down into smaller units - phrases or words - and concepts, then themes were formed (Elo et al., 2014). Two researchers coded the data to improve reliability. With the quantitative (4-point likert scale) data, we reported comparisons of the changes in participants' levels of understanding/ability or confidence before the simulation workshop, immediately after the simulation and after their clinical placement. The SPSS (2015) software package was used to calculate confidence intervals (Cl) and p-values through the Anova test (IBM Corp, 2015).

\section{Results}

Fifty percent of the 71 participants were aged between $18-25$ years of age, and $50 \%$ were 26 years and older (see Table 1). Sixty-six students (93\%) participated in the pre-simulation survey, 61 (85\%) in the post-simulation survey and $29(41 \%)$ in the post-clinical survey. Not all students made comments in the free text sections within each question of the surveys. Many participants had obtained a Higher School Certificate as their highest level of education (a number of these were school-leavers entering the BMid course), 30\% had a previous Bachelor's degree and two had Master's degrees. A quarter of them had experience working with women and infants. These experiences included working as a doula, nanny, or swimming, infant massage or yoga instructor, maternity assistant and a psychology intern with young pregnant women's support groups. The 
previous experience of students may have affected the level of their reported confidence and abilities in the surveys, but this was not accounted for in the analysis.

$<$ Put Table 1 and Figure 1 here>

There were notable changes over time that were apparent from the survey data. Student rates of understanding, ability and confidence levels rose markedly after the workshop (figure 1). For some clinical skills, the proportion of students who reported a reasonable or full understanding, ability or confidence decreased after their clinical placement compared to the post simulation rate.

There were significant changes in students' understanding, ability and confidence regarding six of the nine clinical skills focussed on during the simulation workshop (see table 1). Prior to the simulation workshop, over a third of the students felt they had no confidence in performing a postnatal assessment on a woman ( $36 \% n=23)$. After the clinical placement, only $3 \%(n=1)$ still felt this way, whereas $52 \%(n=15)$ felt somewhat confident and $45 \%(n=13)$ felt reasonably or fully confident in this skill. Student's perceived ability to assist a woman during normal labour and birth was very low presimulation, with $76 \%(n=54)$ having little or no confidence in this skill. After their clinical placement, $52 \%(n=15)$ felt a little confident, and a third of the students $(35 \% n=10)$ felt reasonably confident in this skill-set. Table 1 demonstrates the rates in understanding, ability or confidence in the students from before the simulation workshop, immediately afterwards, and after their clinical placement.

There were five main themes arising from the qualitative data from the post simulation and post clinical surveys. These were 'having a learning experience', 'building confidence', 'identifying learning needs', 'developing communication skills' and 'putting skills into practise'.

\section{Having a learning experience}

The majority of comments were related to feeling that the simulations were positive learning experiences, and that they had learnt through the experience. Post-simulation survey respondents found the learning experience either 'reasonably useful' or 'very useful' ( $84 \% n=61)$. For example, one student stated: 
This exercise was so beneficial on many levels...I think all classes should be structured in this way. This will enable the students to see the theory in practice so much more clearly.\#21

I thought the SIM workshops were all fantastic. ...I also feel I will be able to contribute more fully and earlier in my placement rather than feeling like I am only capable of standing back and watching. This was excellent you should do this every year! And for 2nd and 3rd years with higher skills explored. \#34

The simulation really cemented the techniques and procedure.\#3

The use of small groups within the simulation scenarios was a valuable element of the learning experience for a number of students. Students reported that they felt safe in the environment that was created with the use of small groups, and also the approach facilitators used in supporting learning. This student remarked on the safety she felt in such a group:

The use of small groups was fantastic. The safety and relaxed environment enabled the group to make mistakes and then calmly work through the solutions \#41

Role play activities and realistic scenarios were found to be very helpful. Role playing all the parts in the scenario, for example, the mother, student midwife, support people; helped the students see the situation from a variety of perspectives. For example:

Doing the simulation for the antenatal scene and acting as the midwifery student really threw me in at the deep end and I stumbled my way through it. I surprised myself with how much I actually knew and feel a lot more confident to go into my OSCE and clinical placement for having the opportunity to role play in this scenario.\#22

\section{Building confidence}


Many respondents referred to the value of the simulation project in building their confidence and capabilities prior to their clinical placement. For example:

I feel considerably more confident in all areas than I did before the workshops. I did not feel confident about the OSCE before and now I feel reasonably confident. I also feel I will be able to contribute more fully and earlier in my placement rather than feeling like I am only capable of standing back and watching. Thank-you! \#11

I feel more confident about the upcoming clinical practice as a result of participating in the simulation.\#3

\section{Identifying learning needs}

A number of students found the simulation project to be useful in helping them identify their own learning needs and strengths. This assisted students in approaching the clinical practice setting well prepared, having revised or 'refined' some of their skills, and knowing which ones they needed to improve. One student said:

...I thought the simulation was a great diagnostic measure of where we were at and where we need to be and what we need to work on or learn in order to be at our best for clinical. \#5

...I feel it gave us an opportunity to identify areas upon which we could improve in a safe and caring environment, as well as encouraging us to realise what positive attributes we already possess.\#34

\section{Developing communication skills}

Students rated the experience well in terms of the opportunity to rehearse their communication and interpersonal skills: 
Interacting with the father was important and having positive effects for the father/child relationship in the future. I found it very useful and learnt lots of things about communication and interaction with not just the mother but those supporting the mother too. \#10

Very aware in all clinical situations of special \& inclusive communication and really listening (ie non-dominant positioning, eye level communication, open physically, leaning forward, repeating what she has said, inclusion of partners/support people etc).\#22

In the post clinical survey, students were asked to give two examples where they used skills obtained from the simulation activities in their clinical placement. Communication skills were frequently mentioned, for example:

I was much more confident talking to the midwives and women after the role play scenarios. $\# 12$

Sim week was extremely useful in learning how to communicate with the woman in a real life situation.\#22

[I learnt] how to speak to the women and their families.\#34

\section{Putting skills into practice}

In the post-clinical survey, the students were asked about how they had put the skills they had learnt into practice. Thirty-eight percent $(n=11)$ students mentioned using communication skills they had learnt within the simulations. These ranged from helping women during labour, with breastfeeding, explaining normal postnatal parameters, and answering questions about minor disorders of pregnancy. Many students reiterated that 'knowing what to expect' and developing confidence during their clinical placement was important to them. For example, 'in supporting a woman during normal birth, I used the supportive and encouraging language learned... during clinical I performed a postnatal assessment. I was more confident as I did this in simulation'. \#21 
Half the students who had completed the post-clinical survey mentioned the importance of gaining 'hands on' clinical skills within the workplace, such as: 'Taking blood pressures', 'Abdominal palpations', 'assessing the fetal heart using a doppler', 'postnatal check-feeling for uterine involution', and 'performing an antenatal appointment'. This also extended to skills learnt and put into place within the Delivery Suite. One student stated that she was:

Helping the woman through contractions by telling her to concentrate on her breathing. Involving dad... \#11

Many students commented positively on the work of the facilitators. Descriptors used were 'very engaged and very positive, enthusiastic', 'lovely, insightful and relaxed', and 'supportive and friendly'. One wished for more instruction:

[It would have been good to have] A few tips from the facilitators when students have NO idea! I do understand you wanting us to work it out for ourselves but a little prompting would have been helpful to help us flow. \#19

Other students had ideas of how the sessions could have been more useful:

I would suggest smaller groups of 4-6 so that each simulation can be run twice. Once before [the] instructor has made comments and given feedback. And a second time after feedback [has been] given to see how much we improve and have gained confidence from having done first simulation. Also, this gives other members a chance to play student midwife. \#58

My one piece of feedback would be to do it all like the bathing/nappy changes where there was one facilitator acting like the mother asking us questions. This was VERY realistic and definitely enabled us to use more of our knowledge and skills in a real life situation rather than the student acting as the mother (and being unsure/shy to ask real life questions). I found this the most beneficial and realistic. \#36 
Overall, students felt the simulations were useful and timely, occurring just before their first clinical placement. Students' levels of perceived skills and confidence in antenatal/postnatal assessment, labour and birth care, and neonatal care were enhanced by the simulation workshops.

\section{Discussion}

Similar to other studies, the first year midwifery students considered the use of simulation a positive learning tool that helped them prepare for clinical placement (Mahmood \& Darzi, 2004). The concept of 'knowing what to expect' studied by (Kelly, 2014), in her PhD thesis has identified that when students can anticipate what happens in the workplace, this can lead to contextual experiential learning where students are able to recall simulation experiences. This, in turn, allows students to use their new skills in practical ways, which may have benefits in their beginning levels of care.

Reflecting the findings of Kelly (2014), students in our study perceived confidence and skill levels were improved after the simulations themselves, and many of these were further improved after consolidation and practise in the clinical workplace. However, a proportion of students reported a lesser understanding/ability or confidence with some clinical skills after their clinical placement, compared to the post simulation proportion. One of these skills was the ability to show a woman how to change a nappy or bath her baby. This was not surprising as simulating neonatal care with a doll to performing real neonatal care with the mother present are quite different contexts, hence students' confidence may have lowered after their clinical placement. This shows that simulation should not be used as a replacement for everyday practice but used in addition to clinical practice.

Midwifery is a woman-centred profession which requires high levels of communication skills. These skills are vital in midwifery for quality and safety (Younger, 2012). Simulation to teach and enhance communication in student midwives has been seen to be effective in other studies (Cooper et al., 2012). In particular, using actors/simulated patients in simulations has been seen to be of benefit in this respect (Crofts et al., 2008). Similarly, students in this simulation project felt that the activities helped improve their communication skills. 
The use of actors in simulations was appreciated by students in this study. Employing a simulated patient has been seen to be beneficial to students, including enhancing their problem-solving, decision-making, comprehension and critical thinking skills (Sleeper \& Thompson, 2008). Simulated patients (sometimes known as 'standardised patients') generate a believable situation for students, and can be helpful in rating student's empathy levels (Webster, Seldomridge, \& Rockelli, 2012), something which is not possible with the use of mannequins.

Simulation activities in nursing and midwifery are highly acclaimed by both students and teachers (Reilly \& Spratt, 2007) and they are activities that students cannot do online. Tertiary institutions are currently overhauling their teaching methods in order to attract students away from online courses (O'Connor, 2014). This has involved changing from primarily delivering lectures and tutorials to incorporating collaborative learning activities and inquiry-based learning using internet resources such as podcasts, screencasts, social media, YouTube and digital resources. In line with the work of others, students in our study identified that they found this type of learning enjoyable and stimulating. Given the attrition rates of midwifery students and new graduates, future research could focus on whether simulation activities could be key to the retention of students. Similar strategies have been used for newly graduated nurses to assist with their role transition (Ackermann, Kenny, \& Walker, 2007).

Limitations of this study include those relating to the structure of the simulations, the facilitators and time constraints. The simulations were not tested prior to use and the facilitators were not formally skilled in simulation facilitation and debriefing. There were time constraints hampering the capacity for simulations to be conducted twice; something that has educational merit (Kardong-Edgren, Starkweather \& Ward, 2008). The surveys also relied on student's self-reported perceptions of their confidence, knowledge and skills. Further research could focus on educators' perceptions of students' preparation for practice.

\section{Conclusion}

First year midwifery students felt well prepared for the clinical workplace following the simulation workshops. The workshops have since been embedded into the first year clinical subject. Longitudinal 
studies on the relationship between simulation activities and student's overall clinical experience, their intentions to remain in midwifery, and facility feedback, would be desirable.

\section{References}

Ackermann, A. D., Kenny, G., \& Walker, C. (2007). Simulator programs for new nurses' orientation: a retention strategy. J Nurses Staff Dev, 23(3), 136-139. doi: 10.1097/01.nnd.0000277183.32582.43

Arthur, C., Kable, A., \& Levett-Jones, T. (2011). Human Patient Simulation Manikins and Information Communication Technology Use in Australian Schools of Nursing: A Cross-Sectional Survey. Clinical Simulation in Nursing, 7(6), e219-e227. doi: 10.1016/j.ecns.2010.03.002

Australian Institute of Health and Welfare (2015). Focus on midwives. Canberra: AlHW. Retrieved $11^{\text {th }}$ November 2015, from http://www.aihw.gov.au/workforce/nursing-and-midwifery/midwives/

Ball, L., Curtis, P., \& Kirkham, M. (2002). Why Do Midwives Leave? . London: Royal College of Midwives

Bogossian, F. E., Long, M. H., Benefer, C., Humphreyes Reid, L. J., Kellett, S. E. M., Zhao, I., \& Turner, C. (2011). A workforce profile comparison of practising and non-practising midwives in Australia: Baseline data from the Midwives and Nurses e-cohort Study. Midwifery, 27(3), 342-349. doi: 10.1016/j.midw.2011.03.001

Broussard, L. (2008). Simulation-Based Learning: How Simulators Help Nurses Improve Clinical Skills and Preserve. Nursing for women's health, 12(6), 521-524.

Burns, N., \& Grove, S. (2005). The practice of nursing research conduct, critique and utilization (5th ed.). Missouri: Elsevier Saunders.

Cant, R. P., \& Cooper, S. J. (2010). Simulation-based learning in nurse education: systematic review. Journal of Advanced Nursing, 66(1), 3-15. doi: 10.1111/j.1365-2648.2009.05240.x

Cant, R. P., \& Cooper, S. J. (2010). Simulation-based learning in nurse education: systematic review. Journal of Advanced Nursing, 66(1), 3-15.

Cantrell, M. A. (2008). The importance of debriefing in clinical simulations. Clinical Simulation in Nursing, 4(2), e19-e23. 
Cioffi, J. (2001). Clinical simulations: development and validation. Nurse Education Today, 21(6), 477486.

Cooke, H., Foureur, M., Kinnear, A., Bisits, A., \& W., G. (2010). The development and initiation of the NSW Department of Health interprofessional Fetal welfare Obstetric emergency Neonatal resuscitation Training project. Australian and New Zealand Journal of Obstetrics and Gynaecology, 50(4), 334-339.

Cooper, S., Cant, R., Porter, J., Bogossian, F., McKenna, L., Brady, S., \& Fox-Young, S. (2012). Simulation based learning in midwifery education: A systematic review. Women and Birth, 25(2), 64-78. doi: 10.1016/j.wombi.2011.03.004

Crofts, J., Bartlett, C., Ellis, D., Winter, C., Donald, F., Hunt, L., \& Draycott, T. (2008). Patient-actor perception of care: a comparison of obstetric emergency training using manikins and patientactors. Quality and Safety in Health Care, 17(1), 20-24.

Cummins, A. M., Catling, C., Hogan, R., \& Homer, C. S. E. (2014). Addressing culture shock in first year midwifery students: Maximising the initial clinical experience. Women and Birth, 26(S1), S24. doi: http://dx.doi.org/10.1016/j.wombi.2014.06.009

Disler, R. T., Rochester, S. F., Kelly, M. A., White, H., \& Forber, J. (2013). Delivering a large cohort simulation-beginning nursing students' experience: A pre-post survey. Journal of Nursing Education and Practice, 3(12), p133.

Dreifuerst, K. T. (2012). Using debriefing for meaningful learning to foster development of clinical reasoning in simulation. The Journal of nursing education, 51(6), 326-333.

Durham, C. F., \& Alden, K. R. (2012). Integrating quality and safety competencies in simulation. . In G. Sherwood \& J. Barnsteiner (Eds.), Quality and safety in nursing: A competency approach to improving outcomes (pp. 227-250): John Wiley \& Sons, Inc.

Elo, S., Kääriäinen, M., Kanste, O., Pölkki, T., Utriainen, K. \& Kyngäs. H. (2014) Qualitative Content Analysis: A Focus on Trustworthiness, SAGE Open, DOI: $10.1177 / 2158244014522633$.

Guhde, J. (2011). Nursing students' perceptions of the effect on critical thinking, assessment, and learner satisfaction in simple versus complex high-fidelity simulation scenarios. The Journal of nursing education, 50(2), 73-78. 
Hayden, J. (2010). Use of simulation in nursing education: National survey results. Journal of Nursing Regulation, 1(3), 52-57.

Health Workforce Australia. (2014). NHETSim. Retrieved 20th November, 2014, from http://nhetsim.trainingvc.com.au/

Health Workforce Australia. (2012). Health Workforce 2025 - Doctors, Nurses and Midwives Volume 1. Adelaide, SA.

Health Workforce Australia (The University of Queensland/Monash University Midwifery Curriculum Consortium) (2010). Simulated Learning Environments - Midwifery Curriculum - Final Report. Health Workforce Australia SLE National Project.

IBM Corp. Released 2015. IBM SPSS Statistics for Windows, Version 22.0. Armonk, NY: IBM Corp. Issenberg, B. S., \& Scalese, R. J. (2008). Simulation in Health Care Education Perspectives in Biology and Medicine, 51(1), 31-46.

Kameg, K., Howard, V. M., Clochesy, J., Mitchell, A. M., \& Suresky, J. M. (2010). The impact of high fidelity human simulation on self-efficacy of communication skills. Issues in Mental Health Nursing, 31(5), 315-323.

Kardong-Edgren, S. E., Starkweather, A. R., \& Ward, L. D. (2008). The integration of simulation into a clinical foundations of nursing course: student and faculty perspectives. International Journal of Nursing Education Scholarship, 5, Article26.

Kelly, M. A. (2014). Investigating the use of simulations in enhancing clinical judgement of nursing students to practice as registered nurses. (Unpublished PhD thesis), University of Technology, Sydney.

Kelly, M. A., Hager, P., \& Gallagher, R. (2014). What matters most? Students' rankings of simulation components which contribute to clinical judgement. Journal of Nursing Education, 53(2), 97101. doi: $10.3928 / 01484834-20140122-08$

Kneebone, R. L., Nestel, D., Vincent, C., \& Darzi, A. (2007). Complexity, risk and simulation in learning procedural skills. Medical Education, 41(8), 808-814. doi: 10.1111/j.13652923.2007.02799.x

Levett-Jones, T., \& Lapkin, S. (2014). A systematic review of the effectiveness of simulation debriefing in health professional education. Nurse Education Today, 34(6), e58-63. 
Mahmood, T., \& Darzi, A. (2004). The learning curve for a colonoscopy simulator in the absence of any feedback: no feedback, no learning. Surgical Endoscopy And Other Interventional Techniques, 18(8), 1224-1230.

McCaughey, C. S., \& Traynor, M. K. (2010). The role of simulation in nurse education. Nurse Education Today, 30(8), 827-832. doi: 10.1016/j.nedt.2010.03.005

McGaghie, W. C., Issenberg, S. B., Petrusa, E. R., \& Scalese, R. J. (2010). A critical review of simulation-based medical education research: 2003-2009. Medical Education, 44(1), 50-63.

McKenna L, Bogossian F, Hall H, Brady S, Fox-Young S, Cooper S. (2011). Is simulation a substitute for real life clinical experience in midwifery? A qualitative examination of perceptions of educational leaders. Nurse Education Today, (7):682-6.

Melnyk, B. M. (2008). Evidence to Support the Use of Patient Simulation to Enhance Clinical Practice Skills and Competency in Health Care Professionals and Students. Worldviews on EvidenceBased Nursing, 5(1), 49-52.

Meyer, M. N., Connors, H., Hou, Q., \& Gajewski, B. (2011). The Effect of Simulation on Clinical Performance: A Junior Nursing Student Clinical Comparison Study. Simulation in Healthcare, 6(5), 269-277 210.1097/SIH.1090b1013e318223a318048.

Minichiello, V., Sullivan, G., Greenwood, K., \& Axford, R. (2004). Research Methods for Nursing and Health Science (2nd ed.). Frenchs Forest: Prentice Hall

Nielsen, A., Stragnell, S., \& Jester, P. (2007). Guide for reflection using the clinical judgment model. The Journal of nursing education, 46(11), 513-516.

O'Connor, K. (2014). MOOCs, institutional policy and change dynamics in higher education. Higher Education, 68(5), 623-635. doi: 10.1007/s10734-014-9735-z

Pugh, J. D., Twigg, D. E., Martin, T. L., \& Rai, T. (2012). Western Australia facing critical losses in its midwifery workforce: A survey of midwives' intentions. Midwifery, 29(5), 497-505. doi: 10.1016/j.midw.2012.04.006

Reilly, A., \& Spratt, C. (2007). The perceptions of undergraduate student nurses of high-fidelity simulation-based learning: A case report from the University of Tasmania. Nurse Education Today, 27(6), 542-550. doi: 10.1016/j.nedt.2006.08.015 
Rochester, S., Kelly, M. A., Disler, R., White, H., Forber, J., \& Matiuk, S. (2012). Providing simulation experiences for large cohorts of 1st year nursing students: Evaluating quality and impact. Collegian, 19(3), 117-124. doi: 10.1016/j.colegn.2012.05.004

Savoldelli, G. L., Naik, V. N., Park, J., Joo, H. S., Chow, R., \& Hamstra, S. J. (2006). Value of debriefing during simulated crisis management: oral versus video-assisted oral feedback. Anesthesiology, 105(2), 279-285.

Shinnick, M. A., Woo, M., Horwich, T. B., \& Steadman, R. (2011). Debriefing: The most important component in simulation? Clinical Simulation in Nursing, 7(3), e105-e111.

Sleeper, J. A., \& Thompson, C. (2008). The use of hi fidelity simulation to enhance nursing students' therapeutic communication skills. International Journal of Nursing Education Scholarship, 5, Article 42.

Sullivan, K., Lock, L., \& Homer, C. S. (2011). Factors that contribute to midwives staying in midwifery: a study in one area health service in New South Wales, Australia. Midwifery, 27(3), 331-335.

Tawalbeh, L. I., \& Tubaishat, A. (2014). Effect of simulation on knowledge of advanced cardiac life support, knowledge retention, and confidence of nursing students in Jordan. Journal of Nursing Education, 53(1), 38-44.

Thomas, C., \& Mackey, E. (2012). Influence of a clinical simulation elective on baccalaureate nursing student clinical confidence. Journal of Nursing Education, 51(4), 236-239.

United Nations Population Fund. (2014). The State of the World's Midwifery. Retrieved 25 November 2014, 2014, from http://unfpa.org/sowmy

Warland, J. (2011). Using simulation to promote nursing students' learning of work organization and people management skills: A case-study. Nurse Education in Practice, 11(3), 186-191.

Weaver, A. (2011). High-fidelity patient simulation in nursing education: An integrative review. Nursing Education Perspectives, 32(1), 37-40.

Webster, D., Seldomridge, L., \& Rockelli, L. (2012). Making it real: using standardized patients to bring case studies to life. Journal of Psychosocial Nursing \& Mental Health Services, 50(5), 36-41.

Younger, M. (2012). Problem-solving and communication skills in clinical practice: A reflection. British Journal of Midwifery, 20(2), 135-138. doi: doi:10.12968/bjom.2012.20.2.135 
